\title{
An Analysis of the Balanced Development of Basic Education in Yunnan Ethnic Areas Under the Background of "Internet +"
}

\author{
Luying Gan ${ }^{1, ~ *, ~ H a n ~ S o n g ~}{ }^{2}$ \\ ${ }^{1}$ College of Education, Yunnan Open University (Yunnan Technical College of Industry), Kunming, China \\ ${ }^{2}$ Youth League Committee, Yunnan Open University (Yunnan Technical College of Industry), Kunming, China
}

Email address:

cloudstory@126.com (Luying Gan),37321880@qq.com (Han Song)

${ }^{*}$ Corresponding author

\section{To cite this article:}

Luying Gan, Han Song. An Analysis of the Balanced Development of Basic Education in Yunnan Ethnic Areas Under the Background of "Internet +". Science Innovation. Vol. 8, No. 1, 2020, pp. 22-26. doi: 10.11648/j.si.20200801.17

Received: February 8, 2020; Accepted: April 3, 2020; Published: April 17, 2020

\begin{abstract}
There are many ethnic minorities in Yunnan Province, due to the influence of geographical environment and economic development factors, the development of ethnic areas is relatively backward. Compared with the economically developed provinces in the Middle East, the demand for talent training and basic education promotion is more urgent. Fully implementing the balanced development of basic education in ethnic areas can effectively promote the realization of educational equity, better strengthen ethnic unity, and promote social stability and economic development in ethnic areas. China has made many efforts in the development of ethnic education, which has promoted the development of basic education in ethnic areas of Yunnan Province, however there are still many problems in the development process that have not been fundamentally improved. The arrival of the era of "Internet + " brings us innovative ideas. The concept of opening and sharing has been continuously popular among the people. Educational informatization can effectively solve the current development dilemma and provide the possibility for balanced development of education. This article takes Yunnan Province as an example. It mainly deals with the problems existing in the development of basic education in ethnic minority areas, analyzes the dilemma that affect its balanced development, and puts forward corresponding measures by leveraging information technology in the context of "Internet + Education". Hoping to contribute to the early realization of the balance of basic education in ethnic areas of Yunnan Province.
\end{abstract}

Keywords: "Internet +", Ethnic Areas, Basic Education, Balanced Development, Educational Informatization

\section{“互联网+”背景下云南民族地区基础教育均衡发展探析}

\author{
甘露荣 ${ }^{1 *}$, 宋涵 ${ }^{2}$ \\ '云南开放大学 (云南国防工业职业技术学院) 教育学院, 昆明, 中国 \\ ${ }^{2}$ 云南开放大学（云南国防工业职业技术学院）团委, 昆明, 中国
}

\section{邮箱}

Cloudstory@126.Com（甘露䒯）,37321880@qq.com（宋涵）

摘要: 云南省少数民族众多, 由于地理环境和经济发展因素影响, 民族地区发展较为落后。相对中东部经济发达省份 而言, 其对于人才培养以及基础教育提升的需求更为迫切。全面落实民族地区基础教育均衡发展能有效促进教育公平 的实现, 更好增强民族团结, 促进民族地区社会稳定和经济发展。我国付出诸多努力, 推动了云南省民族地区基础教 育的良性发展, 但发展过程中仍存在诸多问题未能从根本上得以改善。“互联网+”时代的到来, 为我们带来创新的思路, 开放共享的理念不断深入人心, 教育信息化能有效破解当前发展困境, 为教育均衡发展提供了可能性。本文以云南省 
为例, 主要梳理民族地区基础教育发展存在的问题, 对影响其均衡发展的“瓶颈”因素进行分析, 在“互联网+教育”背景 下借力信息技术提出相应解决措施, 以期能为早日实现云南省民族地区基础教育均衡做出贡献。

关键词：“互联网+”，民族地区，基础教育，均衡发展，教育信息化

\section{1. 引言}

云南省是典型的多民族省份, 全省三分之一人口为少 数民族居民, 由于生活环境恶劣、地处偏远、信息闭塞等 因素限制, 大多数民族地区的发展呈相对落后的势态。当 前, 我国在民族基础教育发展过程中付出了诸多努力, 采 取了如三支一扶、挂职锻炼、招收地方定向公费师范生等 各种形式的政策措施，大力推动了云南省民族地区基础教 育的良性发展, 有效缩小了民族地区教育差距。但由于历 史和现实原因, 云南省民族基础教育的发展依旧迟缓并相 对滞后, 发展中存在的诸多问题并未从根本上得以解决。 民族教育的均衡发展并非静态的过程, 我们需要不断开拓 思路发展创新。“互联网+”有效打破了时间和空间限制, 利 用信息技术手段, 为民族地区基础教育带来发展机遇。[1]

通过文献分析, 现阶段我国学者针对基础教育均衡发 展进行一系列研究, 主要集中在教育均衡发展的意义及内 涵、改善措施等方面; 在民族教育信息化方面也进行了理 论探讨和现状分析, 学者更多倾向于研究民族教育信息化 的意义和理论及内涵建设、信息化教学资源建设、教师信 息化教学能力培养、信息技术与课程整合等。[2]而有关 民族基础教育及信息化建设相结合, 利用教育信息化的模 式、手段和方法解决教育均衡困境的研究则较少。本文结 合云南省民族基础教育发展的现状及困境, 研究在“互联 网+教育”背景下如何更好通过教育信息化建设的手段, 深 入解决发展中资金短缺、师资溃乏等限制因素, 探索出能 有效推动云南省民族教育均衡发展的对策, 促进教育公平 的实现、维护民族团结并有效促进民族地区经济发展。

\section{2. 促进云南省民族地区基础教育均衡发展的必 要性}

\section{1. 有利于民族地区早日实现教育公平}

实现教育公平, 首先应从教育的源头上使民族地区学 生享有平等的受教育权利和机会。但由于经济条件限制, 民族地区地方政府虽然采取诸多扶持政策, 依然难以改变 教育资源配置向经济发展较好的县市倾斜的现状。促进云 南省民族基础教育的均衡发展, 我们不但要坚持发展性原 则, 同时也要兼顾差别性原则和补偿性原则。政府对教育 资源配置进行宏观调控时, 要向民族地区适应倾斜, 从资 金投入、政策等方面保障云南省民族地区的学生和城市学 生拥有平等的教育机会, 从而推动教育公平的全面实现。

\section{2. 有利于实现民族团结, 保障民族地区社会稳定}

推动云南省民族地区的基础教育均衡发展, 能更好消 除民族隔阂, 建立民族信任感, 促进民族团结繁荣。云南
边疆地区有典型的多民族特征，如怒江、迪庆等地区，少 数民族人口众多、同多国接壤, 安全稳定问题引起多方关 注。其本究质, 影响民族地区社会稳定和民族团结的主要 原因是外部敌对势力与民族差别。我们应通过加强交流、 沟通以及教育的形式, 对边疆少数民族地区人民进行积极 引导、宣传教育, 坚持“教育为本”, 为当地学生提供良好 的受教育机会, 增强其对国家统一民族团结的认同感。

\section{3. 有利于促进民族地区经济社会的全面发展}

云南省民族地区大多地理环境恶劣, 缺乏留得住的优 秀人才, 导致地区经济发展相对滞后。促进云南省民族地 区基础教育均衡发展, 能有效促进云南省民族地区教育资 源实现合理优化配置, 更好解决当前民族教育存在的困境。 通过为民族地区大力培养技术过硬的专业人才、优秀的管 理者, 进而推动民族地区社会经济全面进步和发展。

\section{3. 云南省民族地区基础教育均衡发展中存在的 问题}

由于地理环境和经济发展因素影响, 云南省民族地区 经济社会发展相对落后, 造成了基础教育发展不均衡的现 象。云南省政府和民族地区地方政府通过大量努力在一定 程度上基本保障了学生享有受教育机会, 但立足于发展实 际, 仍有诸多现实问题有待解决。

\section{1. 民族地区教育经费投入不足，教育资源配置失衡}

由于长期发展中积累的教育发展差距, 云南省民族地 区对教育资源有着更大的需求。但落后的教育观念导致民 族地方政府更重视地方经济发展, 教育领域仅投入微薄的 经费, 有限的教育资源严重向地方重点学校倾斜, 民族地 区基础教育无法获得保障。云南省民族地区多数位于偏远 山区, 学校分布不均, 学生上学往往需要走几十里山路。 就教育资源配置而言, 教室以及基础软硬件教学设施资源 严重贾乏, 更不用提图书室、现代化的教学设备。

“互联网+教育”突破时间和空间的限制，为优质教育 资源共享提供了可能性，但是民族地区信息技术教育落后、 没有多媒体教学设备, 教育需求无法获得保障支持。 [3]

\section{2. 师资苗乏, 结构失衡}

云南省民族地区基础教育教师缺口大, 整体素质不高, 缺乏先进教学、管理方法的指导, 教学质量得不到保障。 由于生存环境相对较为艰苦, 教师待遇差, 教学条件落后 等原因, 虽然政府采取支教、挂职锻炼、定向师范生等相 应政策手段, 但是一两年的锻炼期满后大学生就会向重点 学校或大中城市流动, 民族地区师资缺乏的现象依然相当 严重。 
从师资结构层次上看, 云南省许多民族地区教师队伍 专业不对口、年龄结构不合理、学历偏低。除基础课程外, 体音美英等课程教师严重贵乏, 教师承担多门课程教学任 务是常态现象。学校长期任教的教师大多年龄偏大、学历 不高, 没有受过专业的师范教育, 普遍无法达到国家教学 标准。[4] 受教育培训经费和繁重工作量制约, 留守教师 也很难获得进修和培训的机会, 在专业能力和信息化技术 方面都无法适应现代化的教学要求。

\section{3. 家庭经济条件落后加重教育起点不公平现状}

云南省民族地区多数居民家庭贫困, 没有教育投入的 能力。即使政府在基础教育方面有相应政策补助，但由于 家长大部分文化程度不高, 他们认为教育无法增加孩子的 谋生技能, 反而是家庭负担。这种落后思想观念严重影响 了学生学习的积极性, 也极大阻碍了教学质量的提升, 这 也是导致民族地区教育不公平的一个重要因素。同时, 由 于民族地区经济滞后, 留守儿童比例居高不下, 当地学校 也因师资、活动空间和经费制约, 对于这部分学生的教育 缺乏制度化的长效机制, 使得民族教育发展面临更大的困 境。

\section{4. 民族地区基础教育特色课程资源缺乏}

云南省民族地区的经济发展情况、文化背景、宗教背 景不尽相同, 而在基础教育方面鲜有针对其民族文化及特 色的相应课程设置, 也未针对民族特征进行特色教育资源 的开发，从而影响了民族地区的教育特色化发展和提高。 [5]

云南省民族地区科学文化发展滞后, 由于基础教育薄 弱, 许多学生在后期学习过程中需要不断补习基础知识; 有些学生只会本民族语言而不懂汉语, 而教材大多数是汉 语为主, 他们需要运用更多时间和精力来进行汉语学习, 导致民族地区学生和汉语学生在基础教育方面产生更多 障碍和差距。

\section{4. “互联网+”背景下促进云南民族基础教育均 衡发展的对策建议}

现阶段, 我国基础教育均衡面临着巨大的挑战。在“互 联网 + ”背景下, 我们可借助互联网技术, 通过发达地区 的学校带动, 融合多方优势, 为少数民族地区薄弱学校提 供支持, 以实现学习资源和师资力量共享。[6]笔者提出 如下对策建议, 以期能为解决发展中瓶颈提供有效参考。

\section{1. 优化民族地区教育资源配置, 加大民族教育信息化 投入}

实现民族教育信息化最大的困境是如何满足资金的 投入、设备设施的购置以及维护。而这些问题解决除了依 靠政府扶持外, 还需要社会要形成合力才能促进其跨越式 发展。

首先，云南省民族地区各级政府在开发民族特色文化 的同时，更应加大教育投入力度，制定教育政策时能向民 族地区恰当倾斜, 财政预算时把民族基础教育放在重要位
置经费优先考虑。政府充分发挥权威性实现民族地区教育 资源的优化配置, 通过宏观调控手段在民族教育政策以及 相关制度上做出调整和改革。在教育硬件（校舍改善、运 动场地修建、图书资料、教学设备、校园信息化和办公及 生活设备等方面）加大投入，尤其注重多媒体信息化相关 教学设施建设, 其是促进云南省广大民族地区学生实现优 质教育资源共享的有效途径和手段。[7]同时, 还应进一 步增大监督管理力度, 建立适应民族地区基础教育均衡发 展的教育评估体系, 各部门密切配合, 检查到位、考核严 格, 及时解决存在的问题。其次, 政府应增强和企业合作, 通过政策优惠、合作开发等方式引入企业的资助，将民族 教育的科研成果和民族人才作为其发展的原动力, 来化解 资金的短缺。如开发民族旅游APP做大数据、开发民族旅 游项目等 [8]。

\section{2. 从立法和政策上给予制度保障}

实现教育公平首先要保障享有平等的受教育机会。云 南省可效仿其他省份通过完善教育相关立法的途径, 在资 金投入及政策支持方面加大保障力度，利用法律制度确保 云南省民族基础教育均衡发展的重要地位, 使云南省民族 地区学生享有教育公平机会、过程的愿望早日实现 [9]。 其次, 积极落实国家的相关政策, 中央及地方政府可考虑 制定相关优惠政策来推动教育信息化发展, 通过强力的政 策保证促进民族基础教育均衡的实现。

\section{3. 加强云南省民族地区师资队伍建设}

\subsection{1. 改革完善民族地区教师编制管理制度，提高待遇}

地方政府和教育行政部门可适当对民族地区的教师 编制管理制度进行改革, 打破教师单位编制的身份束缚, 使其能根据地区学校的需要和实际情况进行合理流动。同 时不断推进民族地区的教师职称评定体制改革。

致力改善民族地区教学工作环境并提高教师待遇引 进综合性人才, 引导并鼓励大学生、城镇优秀骨干教师到 这些地区参与教学工作; 对于扎根民族地区的教师, 应进 一步从工资水平、生活补助以及职称评审等方面进行激励, 通过更多的政策和措施使留守教师能安心工作。[10]

\subsection{2. 完善民族地区教师培训机制, 提高信息化能力}

教育行政部门应完善民族地区教师培训体系, 为教师 定期接受培训和进修提供经费保障, 为当地培养更多优秀 骨干教师; 同时可大力促进地方民族师范院校的建设, 增 强与县级教师进修学校合作办学力度, 更好地定向培养 “一专多能”的能留得住的人才; 进一步发展民族教师远程 研修系统平台, 让教师根据自己的能力及需求进行自主学 习和个性化学习。

民族地区教师除进行专业能力培训外, 还应加强信息 技术应用能力培训。要熟练操作多媒体设备, 并学会运用 信息技术手段实现教学资源优化和共享; 能使用多媒体进 行开放教育资源建设, 提高自身教学能力, 为学生提供更 好的学习平台; 能承担部分民族地区基础教育发展模式变 革的研究工作。[11] 


\subsection{3. 构建教师交流机制，推动资源共享}

在科研课题、教学研讨、教师交流培养等方面实现资 源共享, 依靠互联网信息技术, 健全教师交流机制, 促进 民族地区教师教学科研水平的全面提升。民族地区教师可 通过优质网络教学资源进行模仿和深入学习。充分利用地 缘优势, 使教师不断提高多元文化素质。

\subsection{4. 建立民族地区教师运用教育信息素养考核制度}

将教育信息化能力和素养加入到考核中, 激发教师自 我进行学习提升。也可适当举办教育技术能力比赛, 将成 绩与考核及晋升挂钩。

\section{4. 开放资源共享平台, 优化课程设置}

“互联网+教育”实质是通过互联网实现教育资源的优 化配置。我们要积极开发并完善民族教育资源公共服务平 台, 鼓励民族学校充分利用共享优质资源, 逐步探索基于 互联网的民族教育新模式。[12]同时要进一步推动民族在 线课程资源的共享共建, 推广大规模在线开放课程等网络 学习模式。

有学者曾研究过“双师教学”模式, 其通过网络连接, 一端由中国人民大学附属中学的优秀教师进行远程授课, 而另一端由乡村教师在课堂现场配合教学。这种模式对于 民族地区教师而言, 通过长期优秀教师提供示范, 跟踪学 习教学全部过程, 使其教学能力能大幅提升; [13] 同时, 学生也享受了优质的教学资源。我们可以将昆明优质的中 小学作为试点, 来探索这种资源共享模式, 帮助改善民族 地区教育发展不均衡的现状。

\section{5. 加强民族特色课程资源建设}

与其他地区相比, 民族地区的差异性不仅存在于语言, 还在于其文化、传统、人们的意识等方面的差异。云南省 民族地区基础教育的发展除了要跟随现代化的脚步, 也需 要考虑地方和文化特色。我们应增大民族地区教学改革力 度, 调整基础教育的课程内容, 立足于当地教育发展的现 实与民族特色, 逐步摸索出顺应发展需求的民族基础教育 模式, 结合地方特色进行课程资源开发和建设, 推进民族 基础文化教育均衡发展。

首先, 民族特色课程以国家标准课程为主干, 注重开 发与汉语基础教育课程体系相区分的各类课程资源。积极 推进双语教育模式, 将教师培训与教学研讨作为深化双语 教学改革的重要抓手, 使学生能够更好的掌握各类文化知 识。其次, 增加民族特色课程资源的开发建设, 突出民族 地区特殊的文化, 促进其更好传承。再者, 致力于探索新 型民族教育地域化服务的供给方式, 鼓励当地民族教育研 究机构根据该地区的实际需求组织优秀教师团队开发多 媒体课程教学资源, 使学生不受地域和师资限制, 通过网 络进行学习, 实现优质教学资源共享。[14]

\section{5. 结论}

云南省民族基础教育均衡是民族边疆地区稳定和发 展的重要基础。“互联网+教育”是教育信息化发展的新阶
段, 其突破空间和时间的障碍, 为我们实现优质教育资源 共享提供了可能。[15]我们应借力于其带来的创新与变革, 加强政府在教育资源配置中的领导作用、调动多方社会力 量增大投入力度; 致力于建全相关机制, 完善立法; 加强 师资队伍建设; 实现教学资源平台共享共建; 开发民族特 色课程资源等推动云南省民族地区基础教育均衡发展。云 南省民族地区基础教育问题彻底解决还需要较长的时间, 也需要社会各方携手, 期望在多方努力下云南省民族地区 能早日全面实现教育公平。

\section{致谢}

此论文完成之际, 首先向课题组所有成员表示最衷心 感谢和最诚挚的敬意。各位老师在调研和后期数据分析时 给予我很大帮助。衰心感谢所有关心和帮助我的人, 谢谢 你们。

本文为云南省教育厅科研基金资助项目《“互联网+ 教育” 背景下推进云南省民族教育均衡发展探索研究》(项 目编号：2018JS374）的阶段性成果之一。

\section{参考文献}

[1] 陈耀华,陈琳.互联网+教育智慧路向研究[J].中国电化教育, 2016 (9) : 80-84, 135.

[2] 杨方琦,杨晓宏.我国民族教育信息化研究现状与发展对策 [J].现代远程教育研究, 2014（4）.

[3] 赵昊.云南民族地区义务教育均衡发展研究综述 $[\mathrm{J}]$. 继续教 育研究，2013（02）.

[4] 解光穆,马青,杨文芳. 省域城乡义务教育师资均衡发展的现 状与对策[J].教育理论与实践, 2017（20）.

[5] 辛彦.民族文化与基础教育课程整合的困境研究[D].广西师 范大学,2017.

[6] 甘健侯,赵 波, 李艳红. “互联网 + 民族教育”的内涵、价值 及实现路径 [J].学术探索, 2016, （2）.

[7] 陈娟娟,孙瑜,田莉等.民族教育信息资源数字化现状分析与 归因、对策的研究[J].中国电化教育,2013（7）.

[8] 段从宇,甘建侯. 适应、引领与超越:云南民族教育信息化建 设研究[J].学术探索, 2015, (1).

[9] 中国教科院“义务教育均衡发展标准研究”课题组. 义务教 育均衡发展国家标准研究[J].教育研究, 2013（05）.

[10] 胡友志. 发展式均衡: 区域基础教育师资均衡化的新路向基 于基础教育优质均衡发展的政策变革 [J].教育科学研究, 2012（08）.

[11] 王轶, 石纬林, 崔艳辉. “互联网 + ”时代青年教师信息素 养研究 [J].中国电化教育, 2017（3）. 
[12] 梁林梅,陈圣日,许波.以城乡同步互动课堂促进山区农村学 校资源共享的个案研究——以“视像中国”项目为例 $[\mathrm{J}]$. 电 化教育研究,2017,38（3）:35-40.

[13] 王宁邦, 徐博. 互联网+教育均衡背景下城市优质教学资源 乡村创新共享应用模式 $[\mathrm{J}]$. 智能计算机与应用, 2019（3）.
[14] 秦虹, 张武升. “互联网+教育”的本质特点与发展趋向 $[\mathrm{J}]$. 教育研究,2016（6）：8-10.

[15] 陈丽. “互联网+教育”的创新本质与变革趋势 $[\mathrm{J}]$. 远程教育杂 志, 2016 (4) : 3-8. 